\title{
التوليف بين الشريط النسجي والهبال مدخل لاثراء النسجيات اليدوية علي نول المنضدة
}

أ. أ.د / أيمن أحمد العربي

استاذ النسيج بقسم التربية الفنية

كلية النربية النوعية جامعة المنوفية
أ.د / جمعه حسين عبدالجواد

استاذ النسيج المتفرغ ووكيل كلية التربية النوعية لنشئون التعليم التئية

والطلاب، رئيس قسم النربية الفنبة الأسبق، جامعة المنوفية

\section{حنان عبدالعظيم عيسى العيسوي}

الباحثة بقسم التربية الفنية

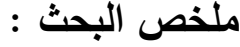

يتميز فن النسيج اليوم بابداع وفكر الفنان معتمدا علي الاساليب والتثنيات النسجية التي

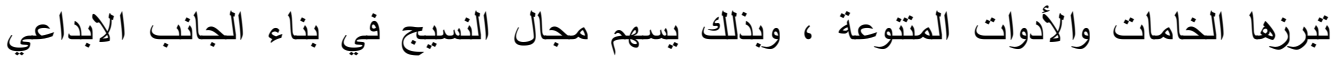

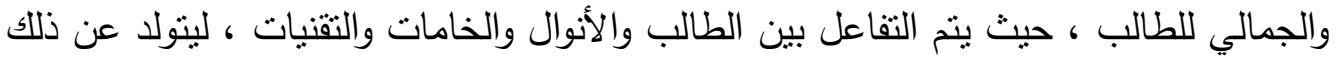

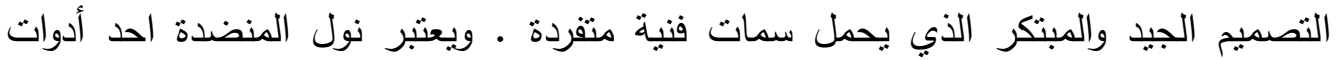
ممارسة فن النسجيات اليدوية بالتعليم العام وبكليات الفنون ـ فمن خلال هذا النول يتم الحصول

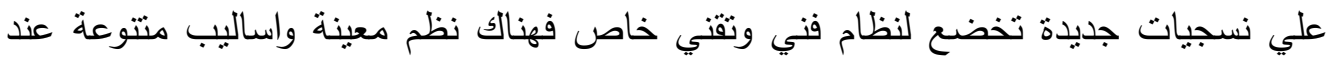

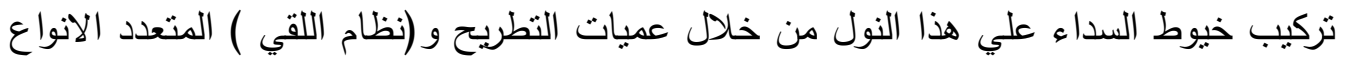

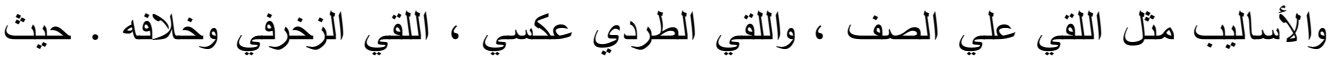

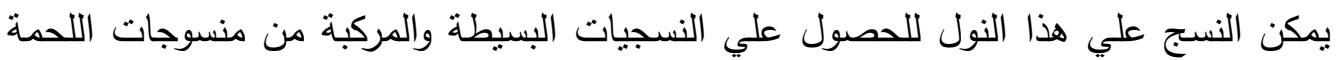

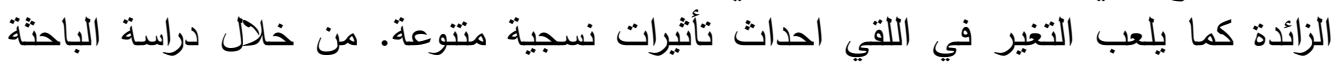

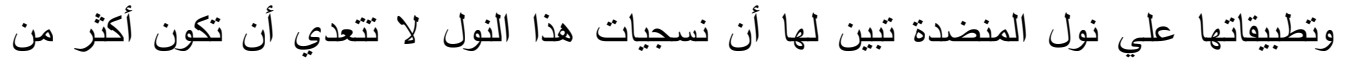

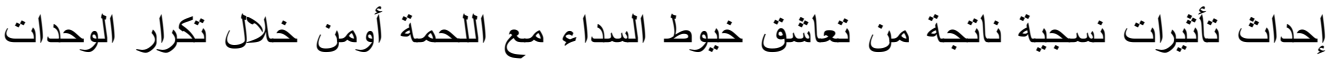

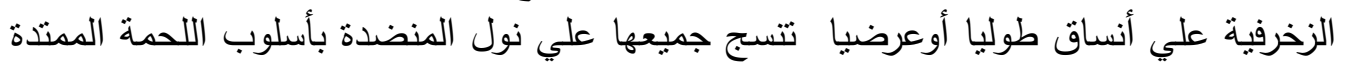

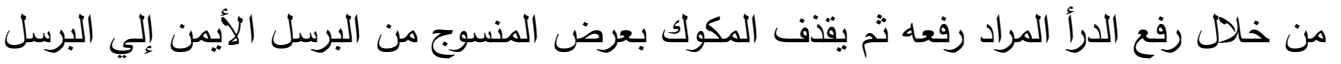

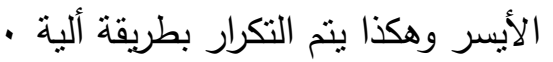

ومن هنا تعد التأثيرات النسجية علي هذا النول تقليدية وفي حاجة إلي إثرائها بالقيم

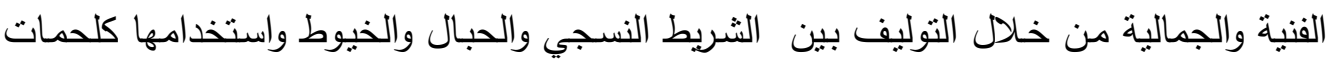

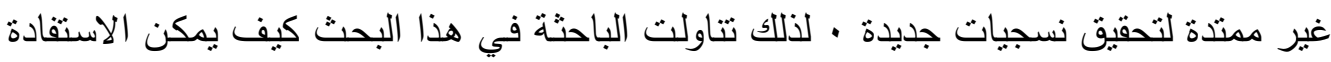

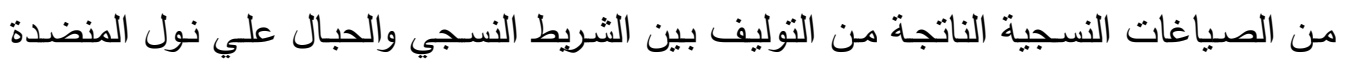

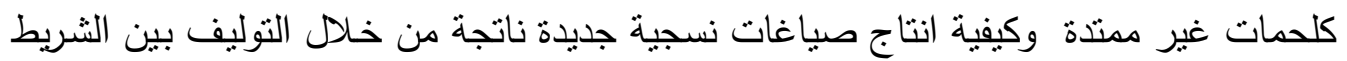

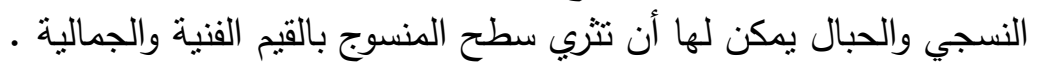




\section{Research Summary :}

The art of weaving today is characterized by the creativity and thought of the artist, depending on the textile methods and techniques highlighted by the various materials and tools, and thus the field of weaving contributes to building the creative and aesthetic side of the student, where the interaction between the student and the looms, materials and techniques takes place, resulting in a good and innovative design that carries unique artistic features. The table loom is one of the tools for practicing the art of handwoven in public education and art colleges. It is through this loom that new tapestries are obtained that are subject to a special technical and technical system. There are certain systems and various methods when installing warp strings on this loom through shredding operations and (the "cast system") of various types and methods such as thrusting on the row, back throwing, decorative finds, etc. Where it is possible to weave on this loom to obtain simple and composite weaves from excess weft textiles, and the change in the material can cause various textile effects. Through the study of the researcher and its applications on table looms, it became clear to her that the tapestries of this loom do not go beyond creating textile effects resulting from the intermingling of warp threads with the weft or by repeating the decorative units in longitudinal or crosswise patterns all woven on the table loom in the style of the weft extending from During the lifting of the shield to be lifted, then the shuttle is thrown in the width of the woven from the right messenger to the left messenger, and so it is repeated in an automatic way.

Hence, the textile effects on this loom are traditional and need to be enriched with artistic and aesthetic values through the synthesis between the weaving tape, ropes and strings and using them as non-extended wefts to achieve new textiles. Therefore, the researcher discussed in this research how to take advantage of the textile formulations resulting from the combination of the tape The weaving and cords on table looms as non-stretched weaves and how to produce new textile formulations produced through the combination of weaving tape and ropes that can enrich the woven surface with artistic and aesthetic values. 
" ويتميز فن النسيج اليوم بابداع وفكر الفنان معتمدا علي الاسـاليب والتقنيات النسجية التي تبرزها الخامات والأدوات المنتوعة ، وبذللك يسهم مجال النسيج في بناء الجانب الابداعي

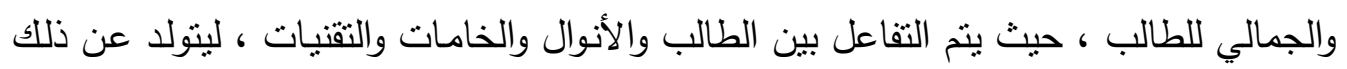

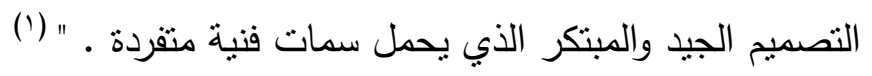
ويعتبـر نول المنضـدة احد أدوات ممارسـة فن النسـيات البدويـة بـالتعليم العـام وبكليـات

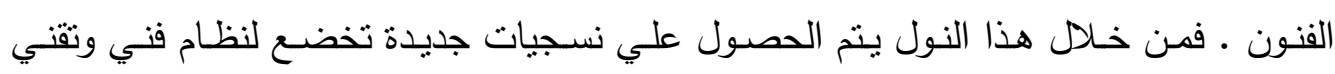
خاص فهناك نظم معينة واساليب منتوعة عند تركيب خيوط السداء علي هذا النول من خلال عميات التطريح و (نظام اللقي ) المتعدد الانواع والأسـاليب مثل اللقي علي الصف مئ ، واللقي

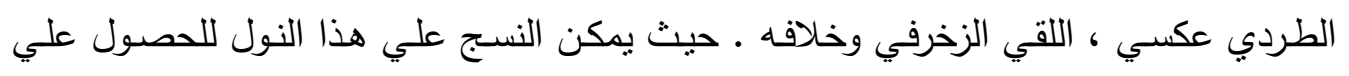

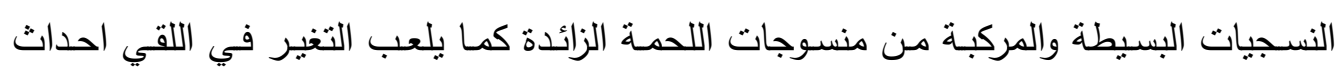

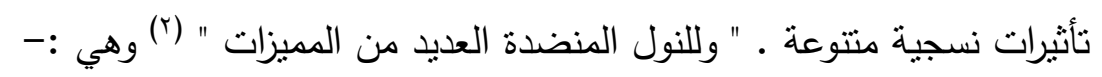

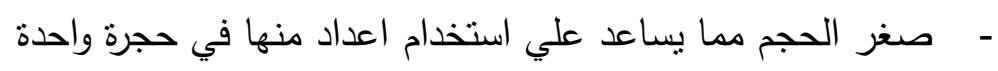
- - تعد ادوات مهمة في تعليم فن النسيج اليدوي

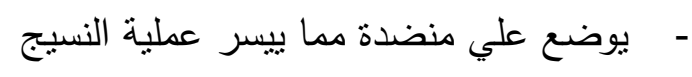

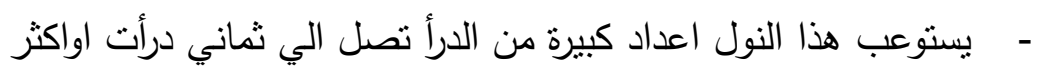
- يتم تتفيذ نسجيات بسيطة ومركبة علي هذا النول

ويعد نول المنضدة اداة مهمة في اثراء الأفكار الابداعية اثثاء الممارسـة العملية عليه او من خـلال مراحل تجهيز هذا النول فيمكن تحقيق العديد من التأثيرات النسجية الجمالية علي

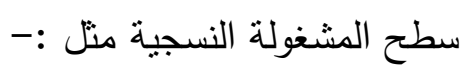
- الثبكية.

سمر سيد حسن (999 (19) : حلول نسجية مبتكرة علي التشييف الناتج عن اللقي الزخرفي لاثراء المعلقة النسجية ، رسالة

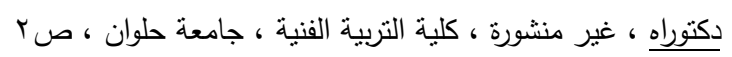

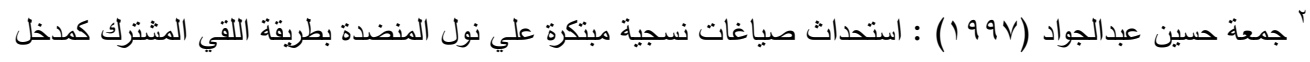

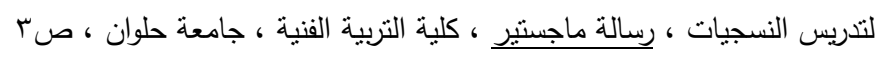


- - تأثيرات نسجية من خلال عملية اللقي -

- أثثرات نسجية من التنوع في عدد فتل السداء في ابواب المشط.

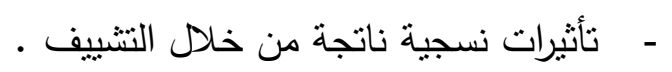

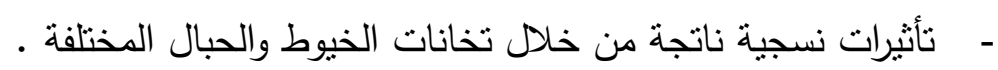

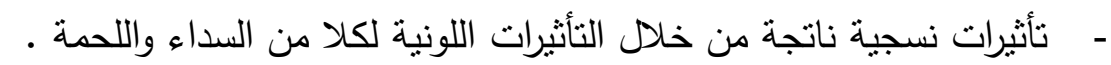

-

-

كل هذه المداخل تعد حلولا من الباحثة لمحاولة الحصول علي التأثنرات النسجية التي تحقق القيم الفنية والجمالية علي سطح المشغولة الفنية المراد تتفيذها ـ كما تهنم الباحثة في هذه الدراسة بالتركيز علي التوليف بين الثريط النسجي والخيوط والحبال كلحمات بمكن استخدامها

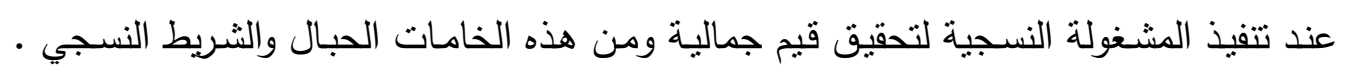
حيث ان الثريط النسجي هو" احد الأسـاليب النتكيلية النسجية ذات الأصسول التاريخية حيث

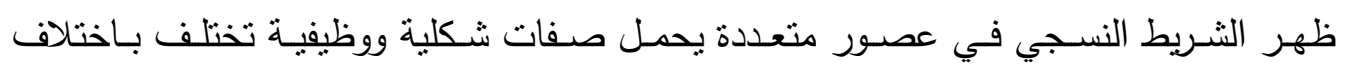

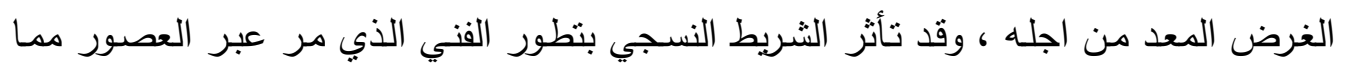

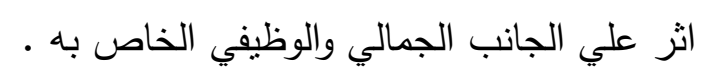

ولهذا تهنم الباحثة في هذه الدراسـة علي عملية التوليف علي نول المنضدة بين الثريط النسجي والذي يحتوي علي ثأثنرات جمالية ناتجة من علاقات خطية متتوعة تحدث من التقنيات

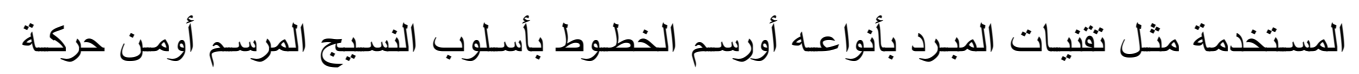
اللحمة الحرة مع استخدام الحبال وتعاثقها وتراكيبها في الصياغات النسجية التشكيلية من خلال التراكب والتجاوز والتشابك واستخدام تخانات الحبال · كل ذلك المتغيرات التشكيلية تعمل علي وتئي

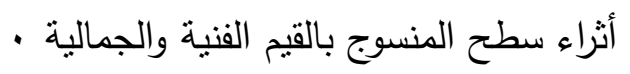

\section{ومن هنا يمكن صياغة مشكلة البحث في هذه التساؤلات :}

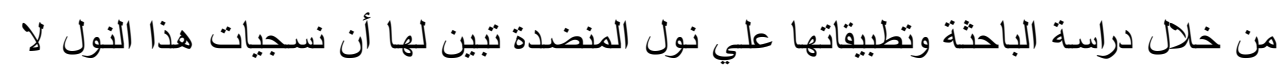

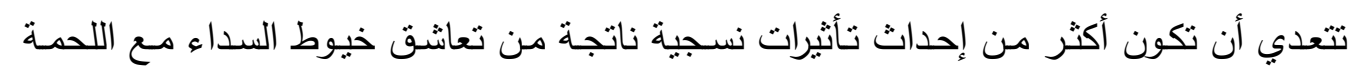

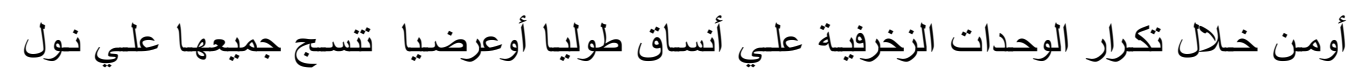

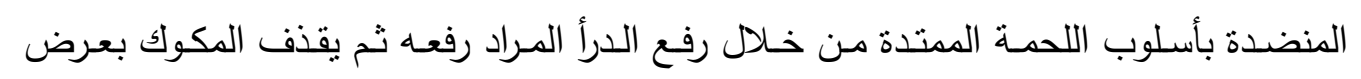


المنسوج من البرسل الأيمن إلي البرسل الأيسر وهكذا يتم التكرار بطريقة ألية .ومن هنا تعد

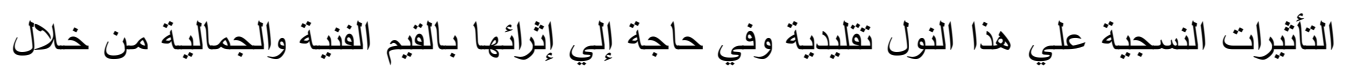

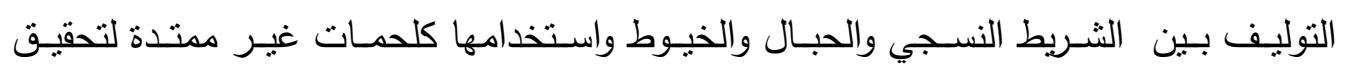
نسجيات جديدة وفي ضوء ذللك تحددت مشكلة البحث في التساؤلات التالية :1- كيف يمكن الاستفادة من الصياغات النسجية الناتجة من التوليف بين الثريط النسجي

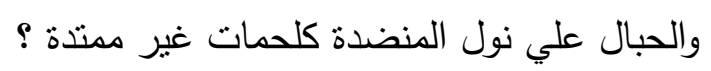

r- الصياغات النسجية الجديدة الناتجة من خلال التوليف بين الثريط النسجي والحبال يمكن لها أن تثري سطح المنسوج بالقيم الفنية والجمالية ؟

$$
\text { أهداف البحث : تكمن أهداف البحث في :- }
$$

1- استتباط صباغات نسجية جديدة علي نول المنضدة.

r- استحداث توليفات جديدة من الثريط النسجي والحبال علي نول المنضدة.

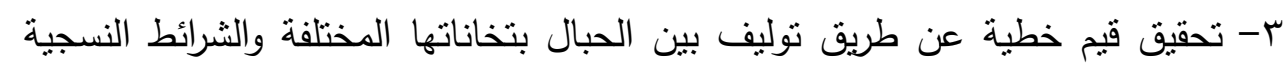
علي نول المنضدة . فروض البحث :

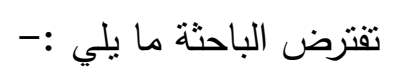

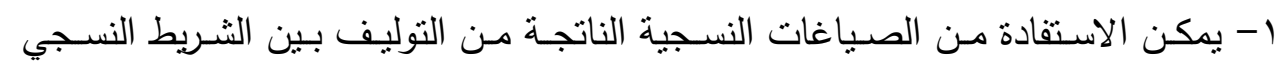

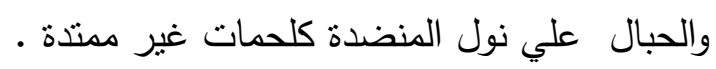
r- قد تثري الصياغات النسجية الناتجة من خله التوليف بين الثربط النسجي والحبال سطح المنسوج بالقيم الفنية والجمالية .

$$
\text { أهمية البحث : أبان }
$$

1- فتح أفاق أوسع للتجريب علي نول المنضدة.

r- فتح أفاق جديدة لتدريس النسجيات اليدوية لدي طلاب التربي التربية الفنية .

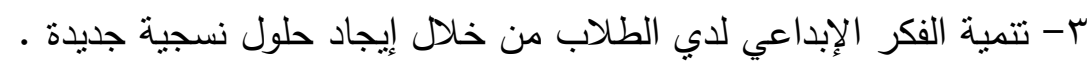
ع - الاستفادة من التوليف بين الثريط النسجي والحبال لتحقيق قيم فنية وجمالية في المعلقات النسجية علي نول المنضدة . 
0- إبراز أهية التوليف كقيمة فنية في مجال النسيج اليدوي

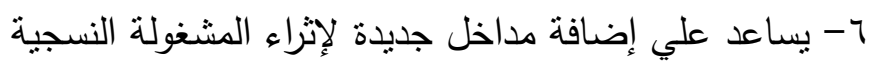

$$
\text { حلتصد البحث : هذا البحث علي :- }
$$

1- استخدام الحبال بأنواعها وتخاناتها المختلفة

r- استخدام شريط نسجي منسوج بأطوال وعروض مختلفة علي نول البرواز

ب- استخدام نول المنضدة ذوالثماني درأت

$$
\text { ع - تجربة ذاتية علي الباحثة }
$$

منهجية البحث :

تتبع الباحثة المنهجين الوصفي التحليلي والمنهج التجريبي من خلال إطارين هما :-

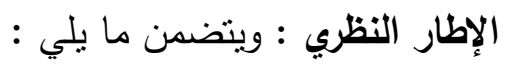

دراسة نول المنضدة والعمليات التحضيرية عليه ودراسة التأثنرات الناتجة من خلال التراكيب النسجية البسيطة والقيم الفنية والجمالية بين التوليف بين الثريط النسجي والحبال علي نول المنضدة لتحقيق روية جمالية والاتجاهات الفنية الحديثة في مجال النسيج اليدوي ودراسة ولئة تحليلية لمجموعة من الأعمال النسجية لبعض الفنانين المصريين والأجانب الذين اتخذوا من الثريط النسجي والحبال مصدرا لرؤيتهم الفنية لئه لئه

الإطار التطبيقي : وتتضمن ما يلي :

- دراسة ذاتية للباحثة لعمل مجموعة من الأعمال الفنية النسجية علي نول المنضدة مع

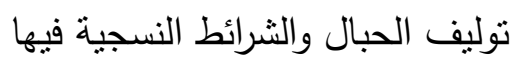
الإطار النظري : النظم:

\section{اولاً : نول المنضدة متعدد الحركات :}

يطلق علي هذا النوع من أنوال المنضدة النول المتعدد الحركات ذلك أن لكل نول حركة من حركات النسج علي هذا النول وسيلة خاصة ، ولذا تتعدد وسائل تكوين النفس لتعطي حرية أكبر عند النسج علية عن نول الدرأة المشط الصلبة .ويعتبر هذا النول من أكثر الأنوال 
شيوعا وهو يحتوي علي أربع أوتماني درأت ويوجد بالتعليم العالي والمعاهد وكليات إعداد معلم التربية الفنية فهو

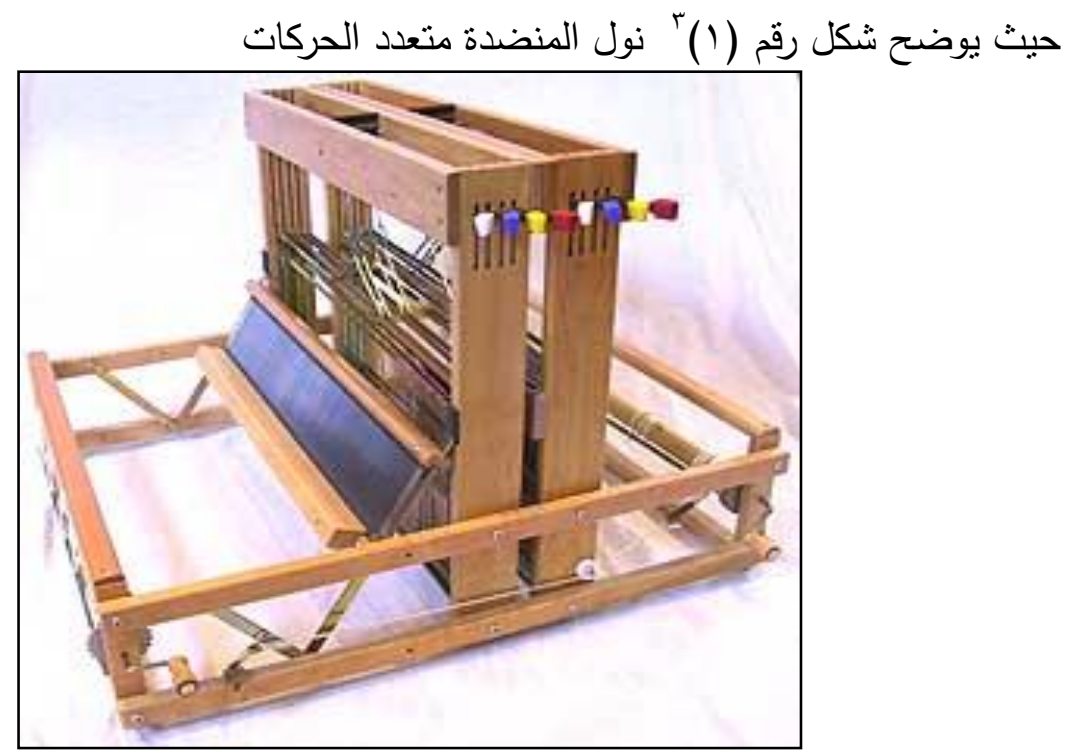

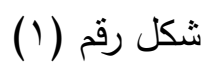

ثانياً : العمليات التحضيرية لتجهيز نول المنضدة : التسدية : " عملية هامة من العمليات التحضيرية في مجال النسيج وتعني تقسيم خيوط السداء

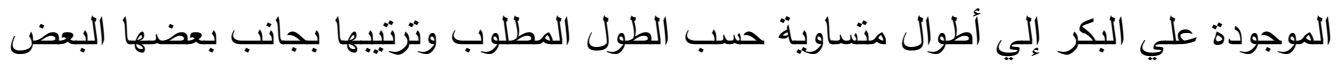

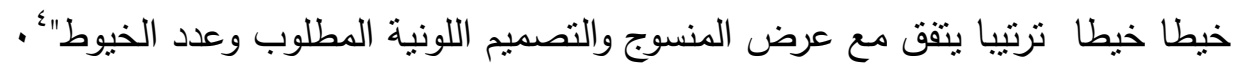

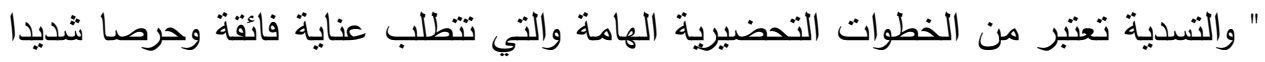

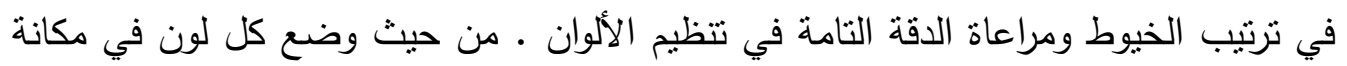

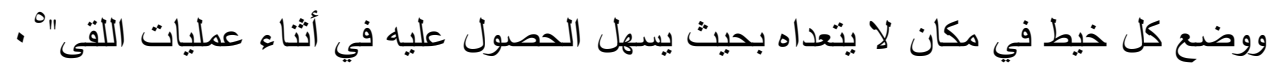

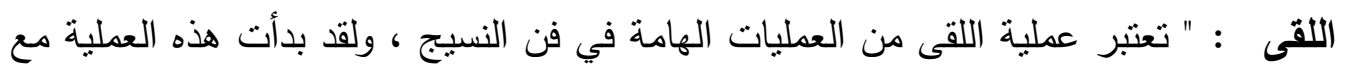

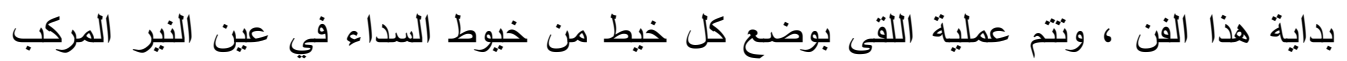

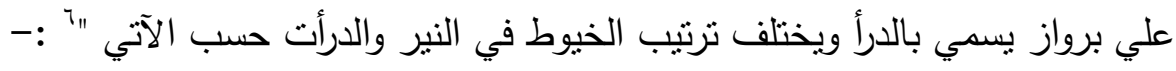

http://keywordsuggest.org/gallery/867902.html ${ }^{r}$

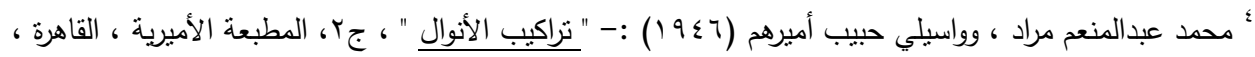

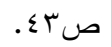

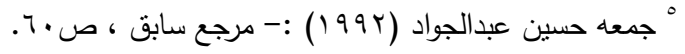




$$
\text { 1- نوع التركيب النسجي المستخدم }
$$

r- عدد الدرأ ونوع النير • إذ تبعا لاختلاف التركيب النسجي يختلف عدد الدرأ المستخدم

$$
\begin{aligned}
& \text { ونوع النير } \\
& \text { r- نمرة خيوط السداء } \\
& \text { ع- عدد خيوط السداء بالسنتيمثر أوالبوصة } \\
& \text { 0- نوع النول }
\end{aligned}
$$

عملية التطريح : "هي عملية توزيع الخيوط في مشط النسيج بعد الانتهاء من عملية اللقى بحيث يتفق مع عدة المشط وعدد خيوط السداء ، وملاحظة عدم دخول خيوط خاصة بياب مع آخر أوترك باب من المشط بدون خيط ويجب ان تتم هذه العملية بواسطة عاملان أمام

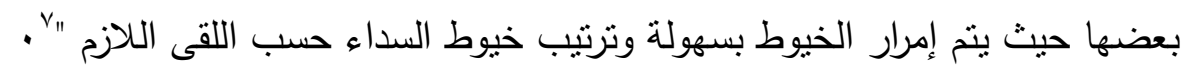
كما أنها عملية توزيع الخيوط الملقاة في الدرأت ، علي مشط النسيج بنوزيع خاص ،

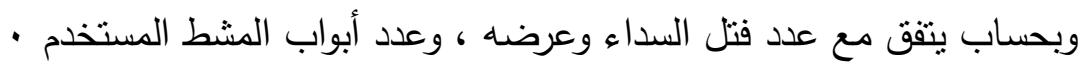

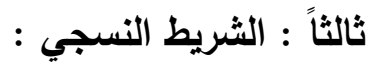
" الثريط النسجي عبارة عن قماش منسوج تحتوي زخارفه علي عناصر زخرفية نباتية أوكتابية أوهندسية أوحيوانية ، والثرائط الزخرفية هي إحدى صور الزخرفة المتمنلة في صور تصميمات تتحرك طوليا بين أطر محددة في اتجاهات مختلفة ، وتتميز عناصرها بالبساطة التهاتيه

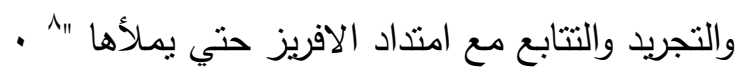
" ويطلق على الثرائط الزخرفية في بعض التقافات الأخرى فن الكيموهيموكما هوفي قارة آسيا في اليابان ، وهوفن التعقيد بأسلوب الجدل والضفر ، وتترجم كلمه كيموهيمو "Kumihimo

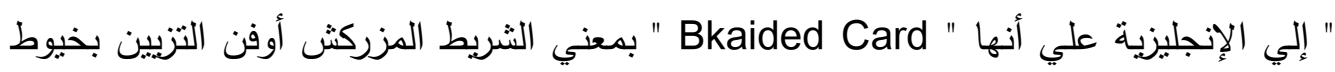

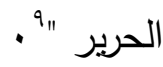

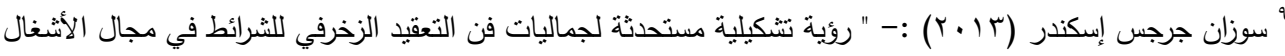

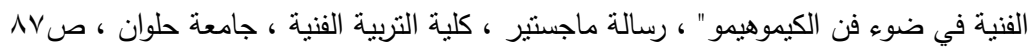




\section{تطوير الشرائط الزخرفية عبر العصور :}

تعتبر الثرائط الزخرفية من الأشكال والهيئات الفنية التي تتاولها الفنان عبر العصور

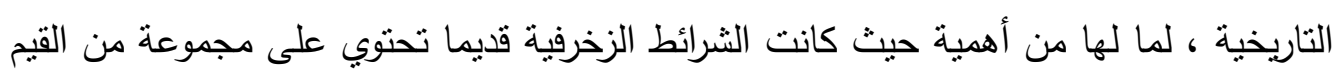
الجمالية والتشكيلية التي تبرز جمالها مثل الزخارف النباتية والهندية وتتوع الخامات الملونة التي نفذت بها الثرائط الغنية بأساليب تقنية مختلفة تبين أحاسيس الفنان تجاه مجتمعة وتعتبر

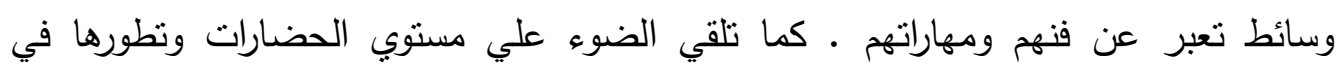
هذا الفن •

\section{الشرائط الزخرفية في العصر الفرعوني :}

إن الفن المصري القديم له طابعة المميز وهذا يعطي مؤشرا عن دور الفنون والحرف اليدوية المصرية وقيمتها التاريخية في العصر الفرعوني ، فقد عرف المصريون القدماء في وقت لتهي

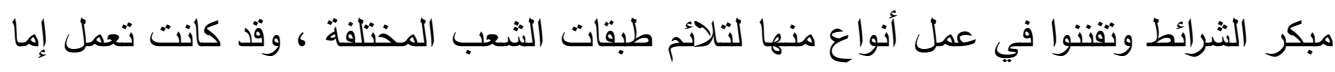

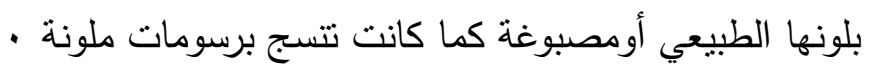

" وقد استخدم المصريون القدماء الثرائط النسجيه في تزيين ملابسهم وفي صنع الأحذية وأشرطة الرأس والكتف والقفازات وجراب السهام ويتضح ذلك من النماذج والقطع النسجيه

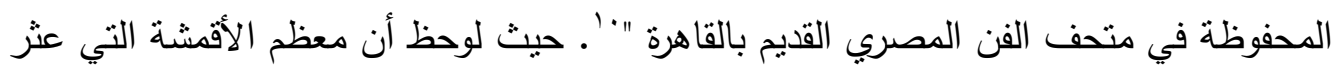
عليها في مقابر الفراعنة وحول أجسادهم منسوجة من الكتان ، كما استخدموا الثرائط في بأي

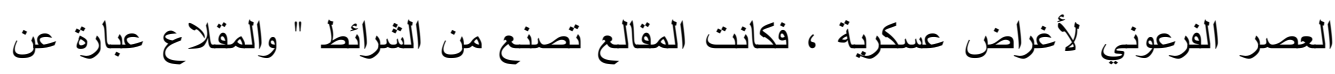

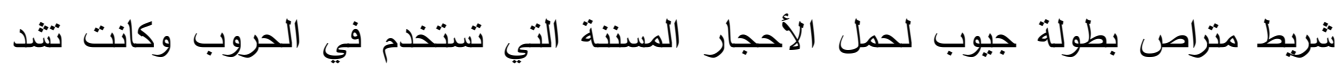

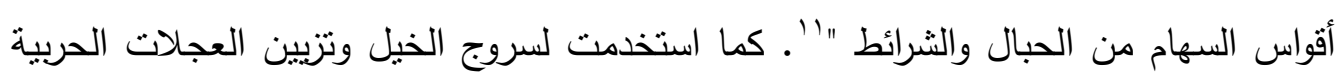
والدروع المتداخلة المربوطة علي البطن فضلا عن استخداماتها المختلفة في الزي والزينة . وقد تميزت الثرائط في العصر الفرعوني بالرسوم الهندية من مربعات وخطوط متعرجة

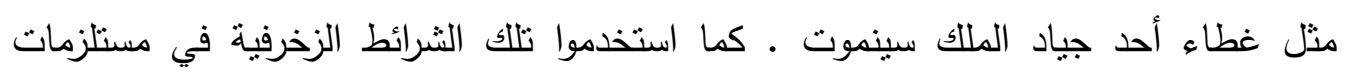

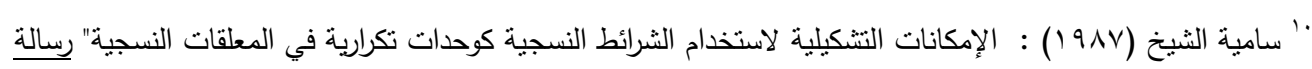

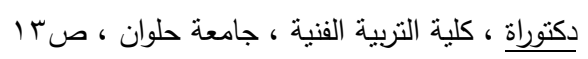

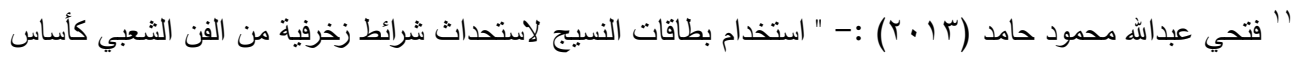

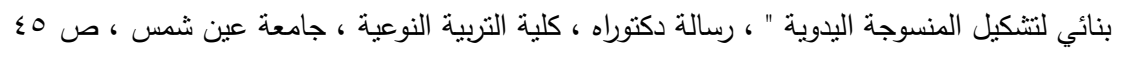




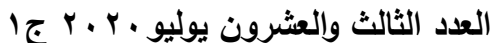
المجلة العلمية لكلية التربية النوعية

حياتهم اليومية مثل الحلي الخاص بهم ، وكرسي عرش توت عنخ آمون وحزامة · كما يوضح

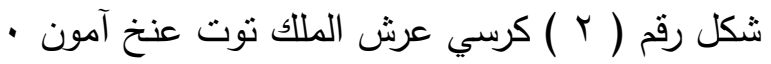

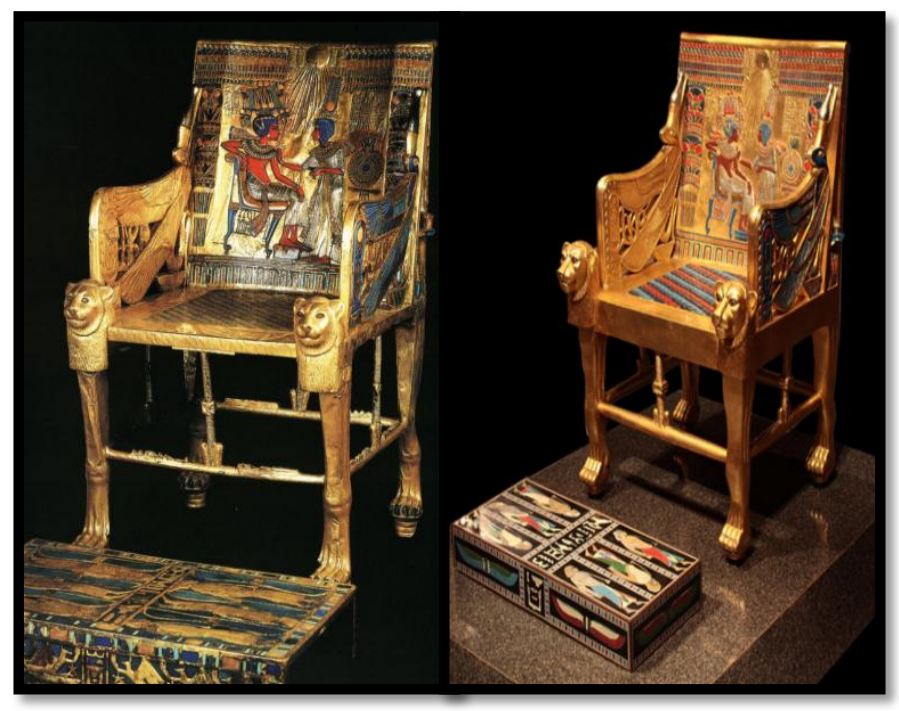

شكل رقم (r) يوضح كرسي عرش الملك توت عنخ آمون

\section{الشرائط الزخرفية في العصر القبطي :}

انتشر استخدام الثرائط في العصر القبطي حيث كانت الثرائط المزخرفة والجامات تتسج

مع الثوب في العصور الأولي ثم أصبحت بعد ذلك تتسج الثرائط المزخرفة منفصلة ثم تضاف إلي الثوب، وفي كثثر من الأحيان نجد شرائط مقصوصة من ثياب قديمة ومضافة إلي

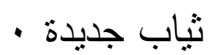

حيث نجد أن القمصان كانت تزخرف من الأمام والخلف بأنشرطة علي الأكتاف تسمي

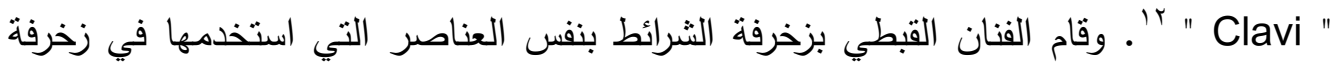

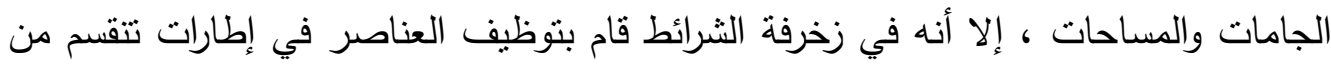
حيث زخرفتها إلي شرائط هندسية وهي أثكال بسيطة ملونة بلون واحد أو أكثر ، "أما الثرائط

وهي كلمه مأخوذة من اللاتينية وهي عبارة عن شريط من النسيج القرمزي يتدلى من وسط الرقبة في القميص الذي يلبسه

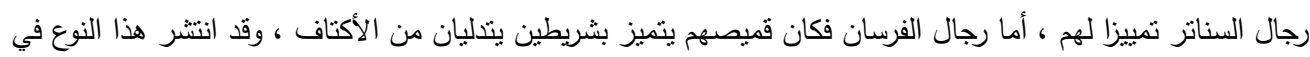

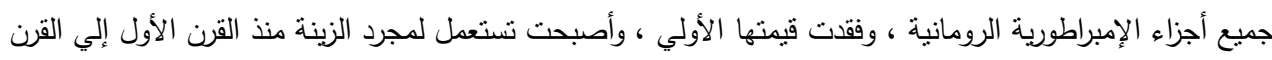
السابع حتي اختفت. 
التي تتضمن زخارف نباتية أوحيوانية فيقوم الفنان بتقسيمها إلي مساحات في صورة دوائر أومربعات أو بخط زجزاجي، ثم يشغل هذه المساحات بعناصر من النباتات أوالطيور

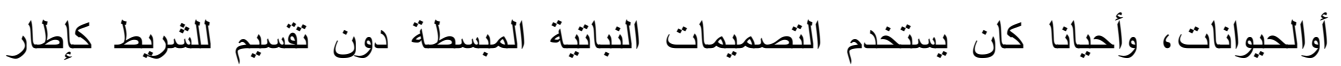

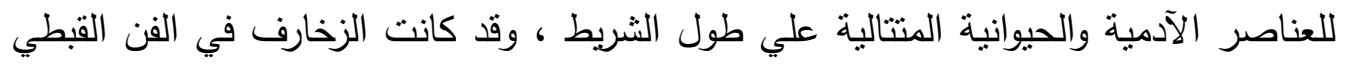

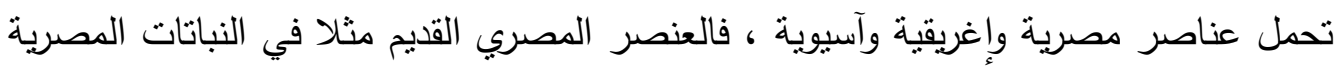

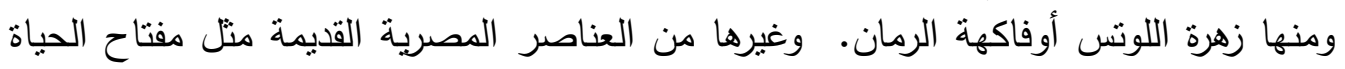

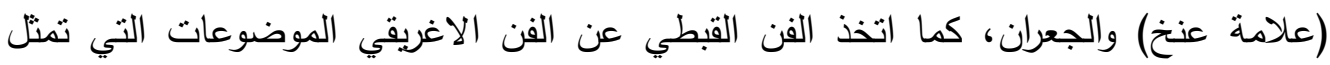

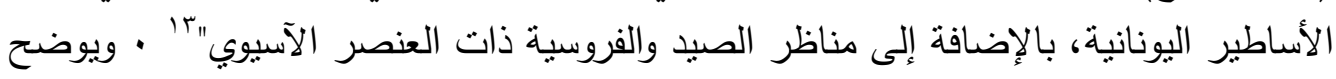

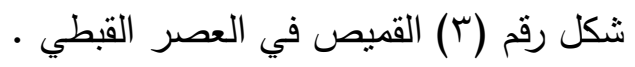

شهرة مصر في المنسوجات قبل ظهور الإسلام ولقد وصلت هذه الثهرة إلي بلاد

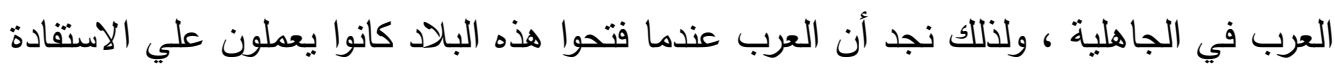

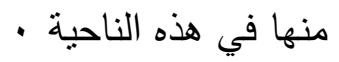

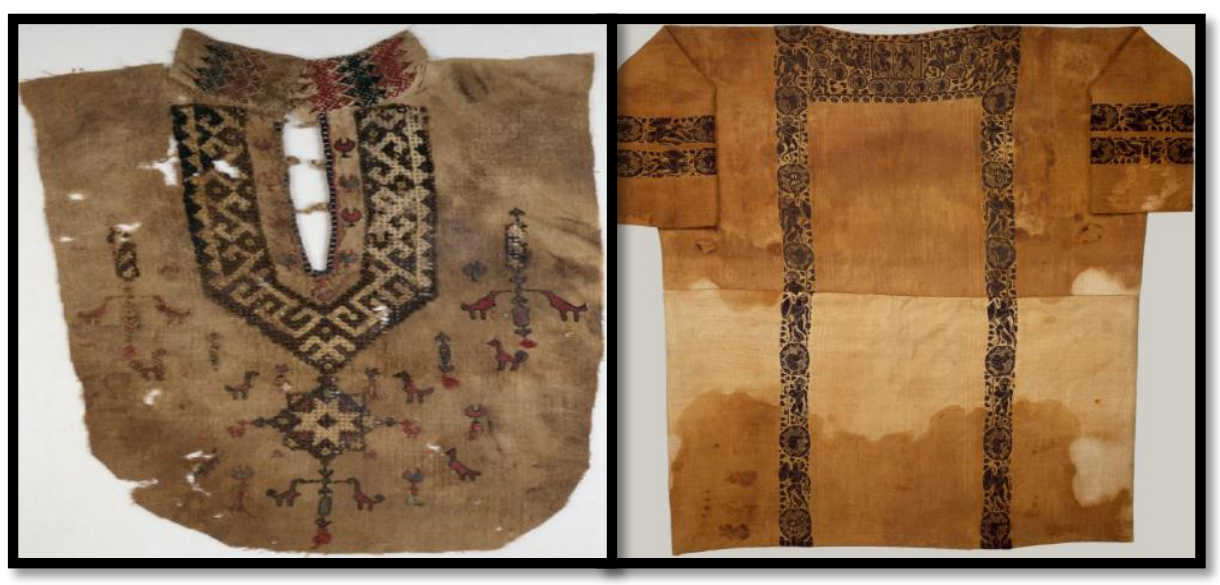

$$
\text { شكل رقم (r) يوضح القميص في العصر القبطي }
$$

ولقد كان من تقاليد العرب وميولهم ما ساعد علي تقدم صناعة النسيج في العصور

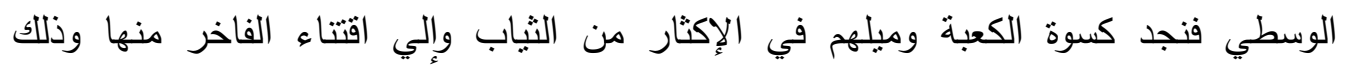

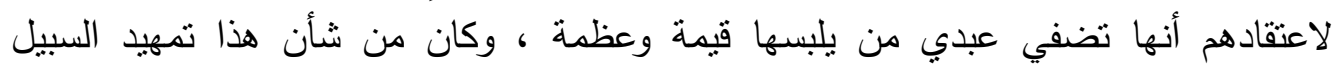

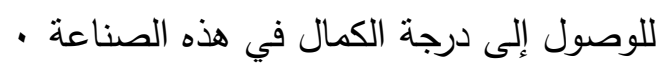


" وعندما فتح العرب مصر منعوا النساجين من نسج الزخارف القبطية وإبقاء ما عداها ، ولكي يثنتوا سلطانهم علي البلاد رأوا أن يضيفوا إلى هذه الزخارف التي أبقوا عليها جملا عربية

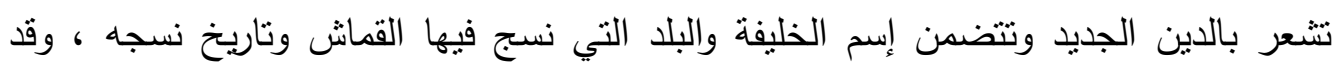

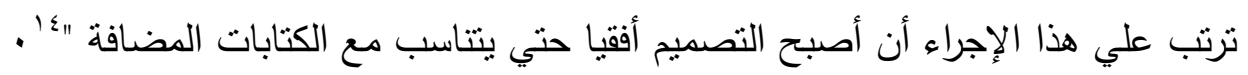
" ولقد استمر إسلوب الثرائط المنسوجة والمستخدمة في العصر القبطي قائمة وواصل المصريون إنتاج الثرائط الزخرفية نحوقرنين من الزمان ، من بداية الفتح الإسلامي لمصر كما

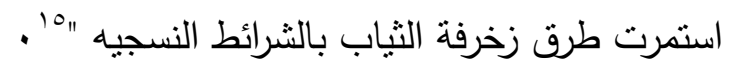

" وكانت أنوال دار الطراز تقوم بإنتاج الثياب السلطانية من الحرير والكتان الفاخر ، وكانت زخارفها تتضمن أثرطة مكتوبة بألقاب السلطان وأنشرطة بها رسوم لحيوانات أومناظر

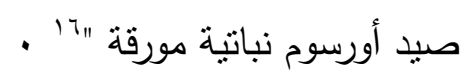

" وكانت الزخارف تتضمن أيضا أثرطة أوجامات مزينة بأسماء السلاطين وألقابهر ،

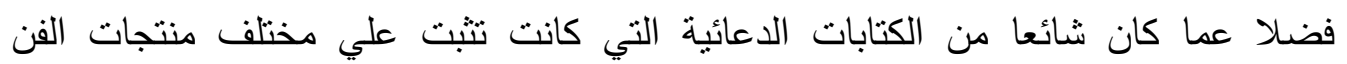

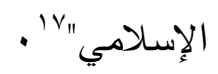

وقد تعددت أنواع الطرق المستخدمة في زخرفة المنسوجات الأيوبي ومنها :1- التطريز باستخدام الذهب والفضة الطنة r- التطريز باستخدام الخيوط الملونة باستخديز

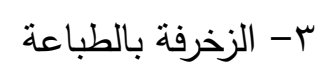

وتتوعت الزخارف الموجودة على المنسوجات الأيوبية من زخارف هندسية وكتابية

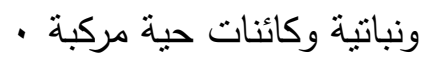

حيث يوضح شكل (ع) قطعة مستطيلة من نسيج الكتان توجد في متحف الفن الإسلامي بالقاهرة ، ويرجع تاريخها إلي القرن السابع الهجري ( الثالث عشر الميلادي) من نـ

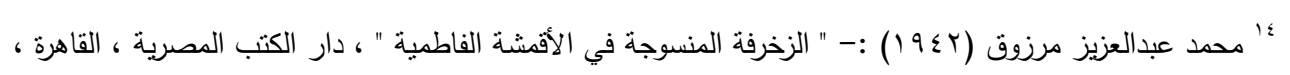

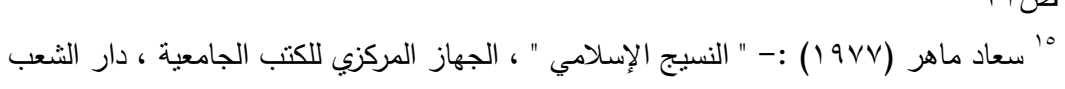

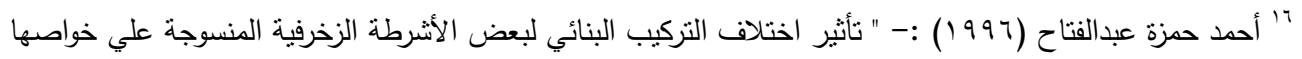

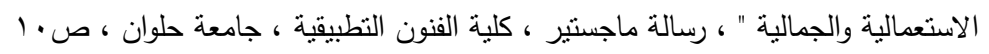

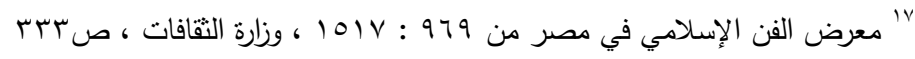


العصر الأيوبي ، حيث تحتوي زخارف الثريط الأوسط علي زخارف هندسية ونباتية ونقوش

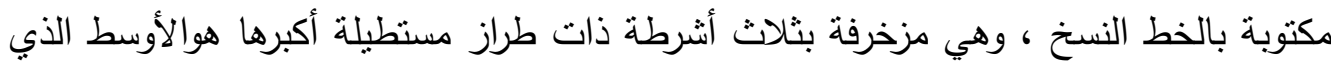
يحتوي علي عبارة نصها ( سعادة ونعمة مخلدان ) وهي عبارة مكررة تفصل بينها زخارف نبانية

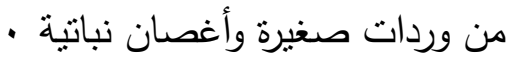

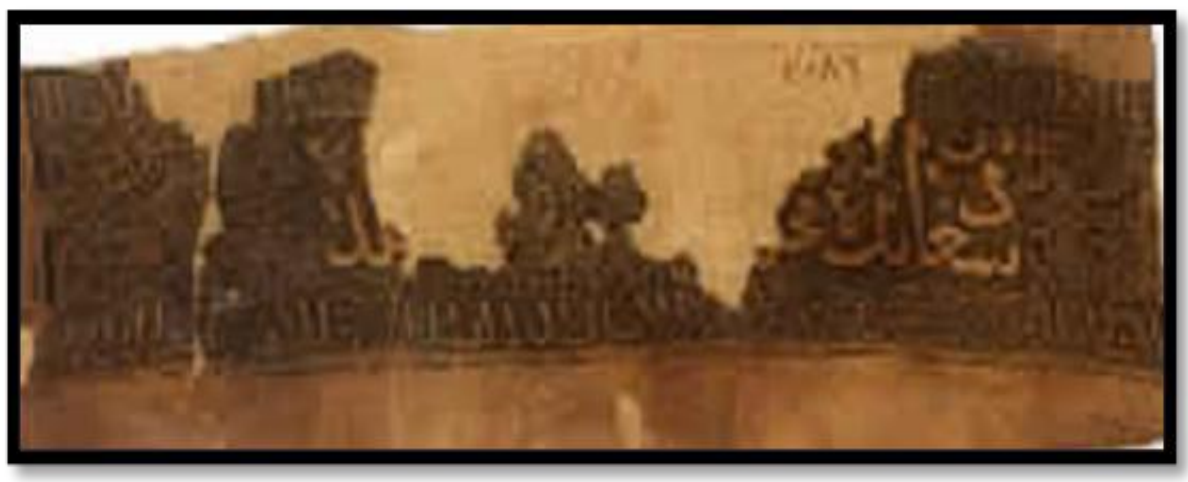

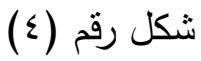

يوضح قطعة مستطيلة من نسيج الكتان توجد بالمتحف الإسلامي بالقاهرة

التجرية العملية للباحثة :

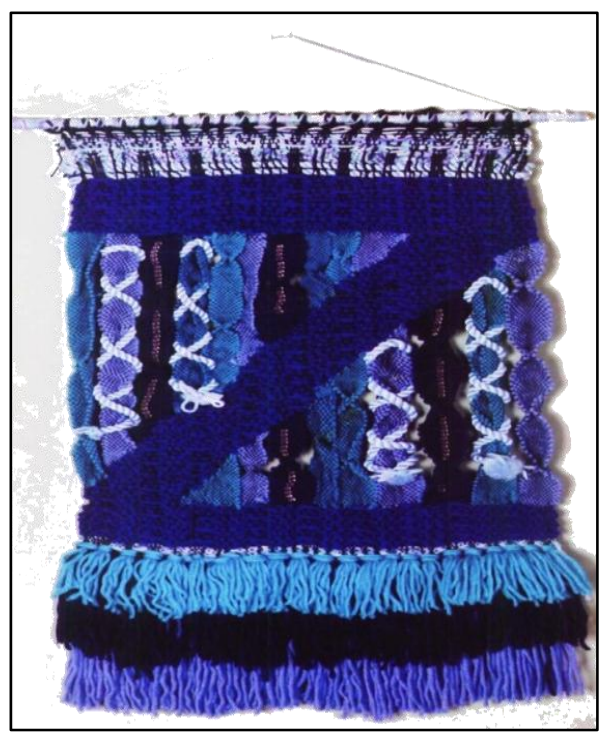

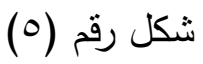

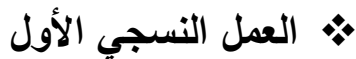

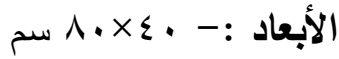

النول المستخدم :- نول المنضدة ذوالثماني

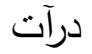

الخامات المستخدمة :- خيط قطن أزرق اللون للتسدية ، صوف ، حبال ، خرز تعليل العمل :يوضح الثكل رقم ( 0) مظهر المنسوج واستخدام تحريك الدرأ كما موضح في الثكل مع 
نسج أقلام طويلة باللون الأزرق ودرجاته من الخيوط السمكية مما أدى إلى تشكيل أقلام طويلة من الثرائط النسجية

أكسبت العمل نوعاً من الحركة الانسيابية الهادئة التي تخلاها تداخل إيقاعي نتيجة استخدام لحمات سميكة من الخيوط الزخرفية وسط هذه الأقلام الطولية لتحقيق التتوع الإيقاعي لتئي بمساحات التصميم ، كما نسجت بعض اللحمات باللون الأزرق أعلي وأسفل هذه الأقلام حيث ظهرت بالتبادل داخل التصميم مع استغلال جماليات التعاشق بينها وبين خيوط السداء ، وذلك الك الك للحصول على تأثنرات نسجيه زخرفية.

كما تم التطريز بالخرز والحبال في تشكيلات متكررة أَثرت السطح المنسوج بالتتوع

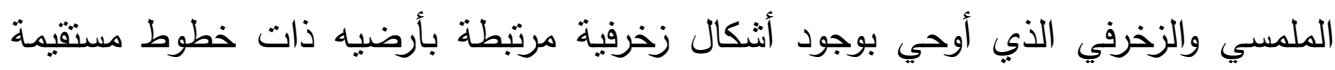
تكونت على أثرها أيضاً عناصر زخرفية مما حقق عنصر الربط بين الثكل والأرضية بهذه بـانه

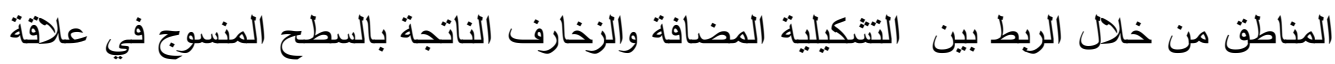
تكاملية حققت منظومة جديدة للصياغات النسجية على أنوال المنضدة .

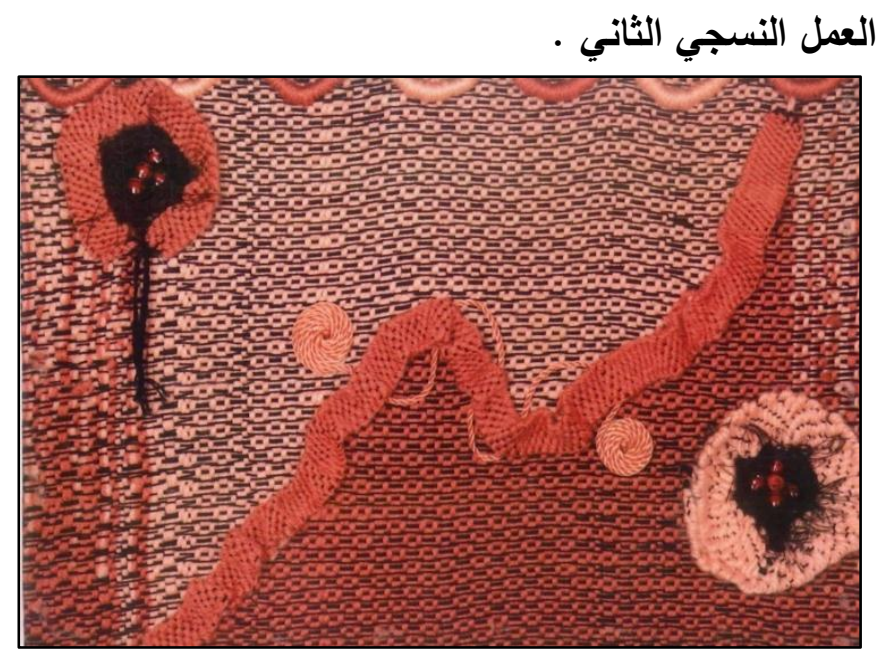

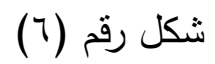

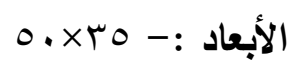

النول المستخدم :- نول المنضدة ذو الثماني درآت. 
الخامات المستخدمة :- خيط قطن اسود اللون للتسدية ، صوف ، حبال ، برواز خشبي ، شرائط نسجيه تحليل العمل :-

في هذا الثكل تم الاعتماد علي توزيع العناصر الزخرفة كما توضح الصورة رقم (؟) من

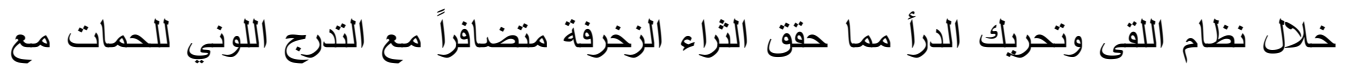

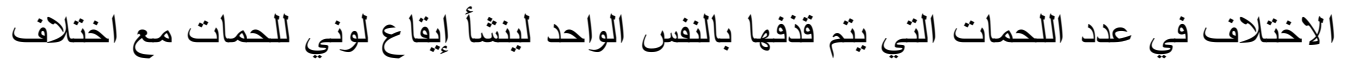
عدد اللحمات التي يتم قذفها بالنفس الواحد ، كما استخدمت الباحثة التدرج بين اللون الفاتح (الروز) مع تداخل بسيط من اللون البرتقالي في الجهة اليسرى من العمل الفني، وفي الجهة اليمني من العمل استخدمت الباحثة اللون الغامق ( البرتقال ) لإثراء العمل الفني بالاتزان. كما تم التشكيل بالثرائط الزخرفية والجبال علي سطح المشغولة النسجية فبدت المساحة كأنها عدة مستويات عن الأرضية ، مما حقق العديد من الأشكال الزخرفة التي نم تتفيذها علي لماني أنوال المنضدة مما أثرت السطح بصياغات نسجيه مستحدثة علي هذه الأنوال اليدوية .

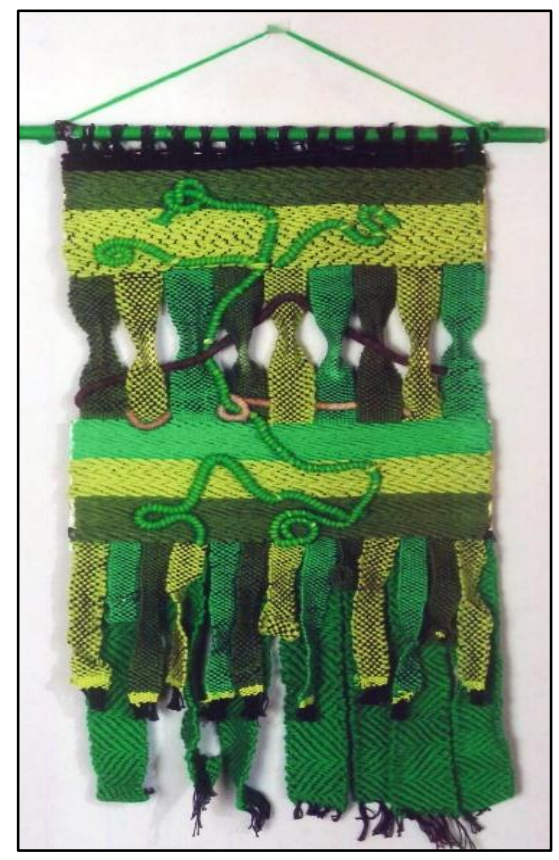

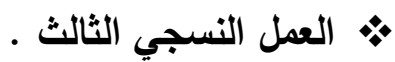

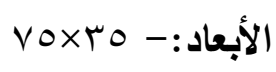

النول المستخدم:- نول المنضدة ذوالثماني درآت الخامات المستخدمة:- خيط قطن اسود اللون للتسدية، صوف ، حبال ، شرائط نسجيه

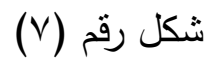


الثكل رقم (V) يوضح مظهر المنسوج الذي يمثل التجربة الذاتية الثالثة الباحثة ، حيث يظهر أسفل العمل مجموعة من الثرائط الزخرفة مختلفة الألوان والأحجام نسجت علئ علي نوله المنضدة ويعلم هذه الثرائط زخارف موزعة علي محور أفقي بأبعاد متساوية تتحصر مع تكرار هذه الخطوط الموجية حول محور التماتل مما أعطي إحساساً بالتدرج بين عدة مستويات وكأنها موجات بحر متلاحقة.

وتوضح المساحات المنسوجة الخطوط المبردية المتموجة الني ظهر بها هذا التدرج الذي أكسب السطح إيقاعاً لنقل حركة تلك الخطوط المتموجة من الاتجاه الرأسي إلي الاتجاه الأفقي

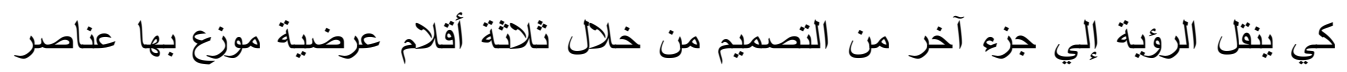
زخرفية من الوحدات السداسية ، ثم تعلوهذه الزخارف مجموعة من الشرائط منساوية الأحجام باللون الأخضر ودرجاته حيث نسجت بطريقة طولية في العمل النسجي لتتوسط مجموعة من

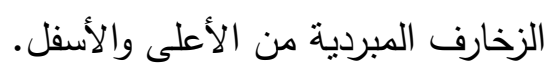

وتعلوتلك الثرائط أيضاً خط أفقي مبردي باللون الأخضر الفاتح وتوضح حركة تلك الخط انثناء وليونة لنتبادل معه في حركته خط أفقي باللون الزيتي ليحدث تتاغم إيقاعي بين حركة

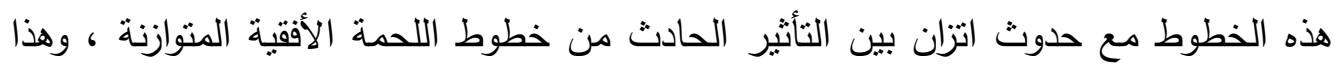
يؤدي إلى الاستقرار في أجزاء التصميم رغم الحركة المستمرة لتلك الخطوط المبردية المنحنية. وبعد انتهاء العمل النسجي علي نول المنضدة تم استخدام خيوط الحبال ذو اللون

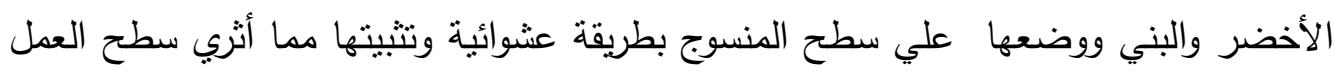
الفني بالتتاغم والإيمان مع إكسابها طابع الحركة كأنها طريق يخترق مساحات شاسعة ذات ذات

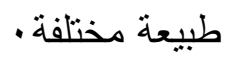
النتائج :- (20) - n في هذه الدراسة نوصلت الباحثة إلي النتائج الآتية :-

1. يعتبر نول المنضدة مصدر إلهام لطلاب التربية الفنية للحصول علي نسجيات جديدة r. توصلت الباحثة إلي نسجيات جديدة من خلال التوظيف بين الثريط النسجي والحبال 
r. النسجيات التي حصلت عليها الباحثة تضمنت قيماً فنية وتشكيلية متعددة أضافت ثراءاً

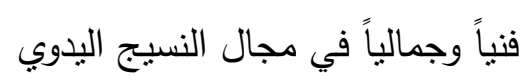

ع. أن لن لنول المنضدة أهمية في اكتساب مهارات تساعد في المستقبل علي استغلالها

$$
\text { كعمل وحرفة تساندنا في الحياة }
$$

๑. أمكن التوصل إلى مداخل تدريسية في استخدام نظم اللقى المختلفة ( لقي زخرفي ، لقي علي الصف ، لقي طردي عكسي ) في الحصول على صياغات نسجيه مبتكرة على نول المنضدة اليدوي 7. أمكن الحصول على عناصر زخرفية منتوعة ناتجة من إختلاف التركيب النسجي والتي يتم تنفيذها على أنوال المنضدة اليدوية من خلال استخدام نظم اللقي المختلفة

$$
\text { توصي الدارسة بما يلي :- (- ت }
$$

ا. مواصلة الدراسات في مجال تطوير الأداء علي أنوال المنضدة اليدوية للإستفادة من

$$
\text { إمكانياتها التدريسية والفنية }
$$

r. توصي الباحثة بضرورة الإستفادة مما توصل إلبه البحث الحالي من الكثف عن أهمية

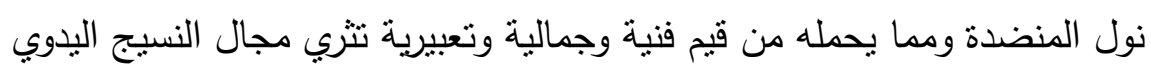

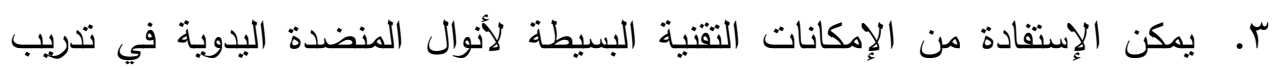

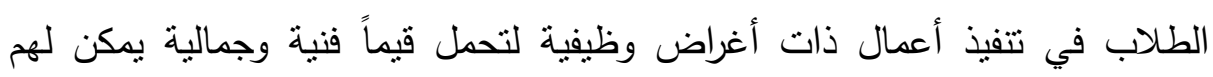
الإستفادة المادية والفنية والمهارية من خلال عمل وحدات إنتاجية كتسجيعهم ولاستخلال

$$
\text { طاقتهم ومواهبهم ومهاراتهم التدريبية }
$$

ع. الإستفادة من نظم اللقي ( لقي زخرفي ، طردي عكسي ، لقي علي الصف ) التي تم

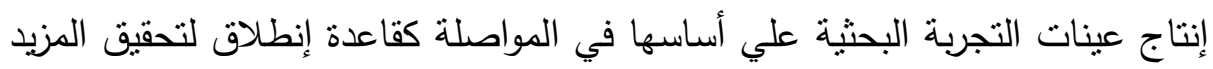
من الثراء في تشكيل الأسطح المنسوجة على أنوال المنضدة البدوية

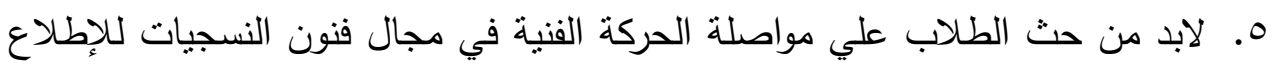

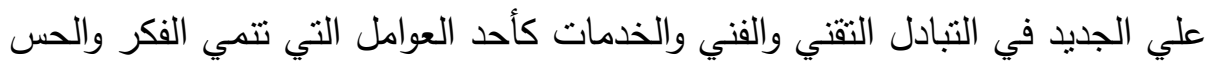
الجمالي والإدراكي لدي الطلاب 


\section{المراجع}

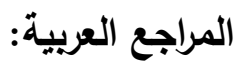

ا. أحمد حمزة عبدالفتاح (997 (197) : " تأثير اختلاف التركيب البنائي لبعض الأشرطة الزخرفية المنسوجة علي خواصها الاستعمالية والجمالية " ، رسالة ماجسنير ، كلية الفنون

التطبيقية ، جامعة حلوان ، صنوجه

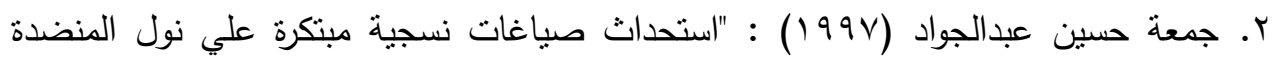
بطريقة اللقي المشترك كمخل لتدريس النسجيات" ، رسالة ماجستير ، كلية التربية

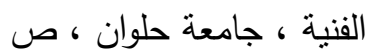

r. سامية الثيخ (99V ( ) : "الإمكانات التشكيلية لاستخدام الثرائط كوحدات نكرارية في تصميم

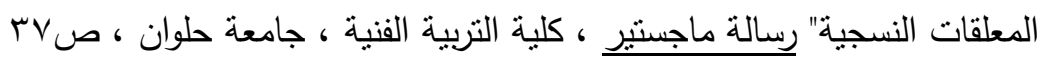

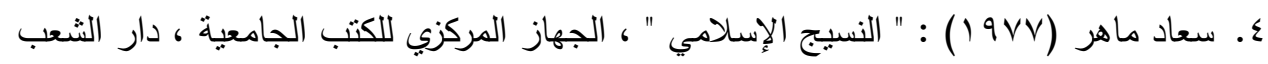
ه. سمر سيد حسن (999) : (99 حلول نسجية مبنكرة علي النتييف الناتج عن اللقي الزخرفي

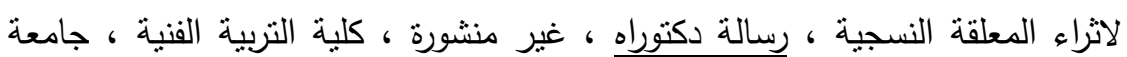

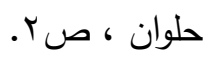

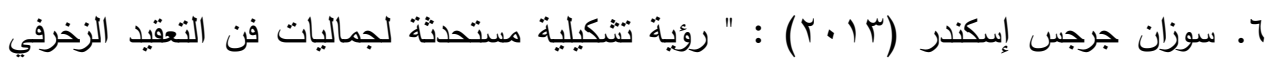
للشرائط في مجال الأشغال الفنية في ضوء فن الكيموهيمو" ، رسالة ماجستير ، كلية

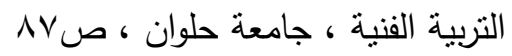

V. فتحي عبداله محمود حامد (T ( †) :- " استخدام بطاقات النسيج لاستحداث شرائط زخرفية من الفن الثعبي كأساس بنائي لنتكيل المنسوجة اليدوية " ، رسالة دكتوراه ، كلية

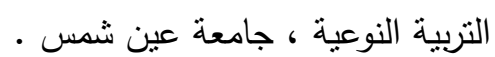
1. محمد عبدالعزيز مرزوق (Y\&9 1) :- " الزخرفة المنسوجة في الأقمشة الفاطمية " ، دار الكتب المصرية ، القاهرة.

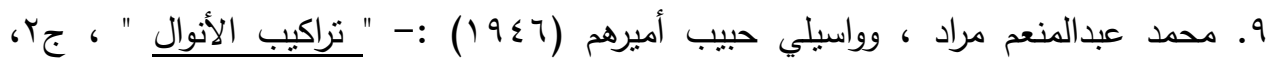

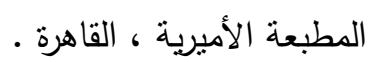

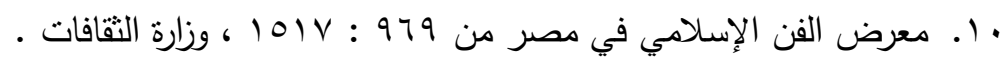

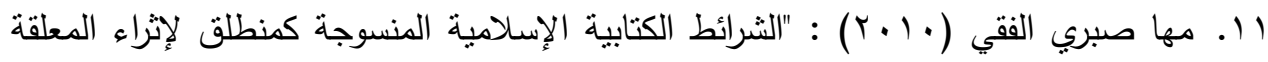

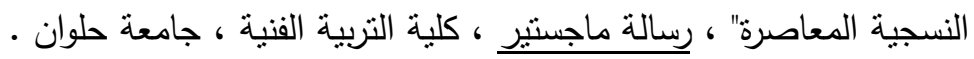

